\title{
PENGARUH MACAM MEDIA DAN PGPR TERHADAP KEBERHASILAN STEK TANAMAN KARET KEBO (Ficus elastica)
}

\author{
Isna Roslyana1), Tri rahayu1), Libria Widiastuti ${ }^{1)}$ \\ 1)Program Studi Agroteknologi Fakultas Pertanian Universitas Islam Batik Surakarta, \\ email : airakiranahebat@gmail.com
}

\begin{abstract}
ABSTRAK
Penelitian bertujuan untuk mengetahui pengaruh macam media tanam dan pemberian konsentrasi PGPR terhadap keberhasilan stek tanaman karet kebo (Ficus elastica). Penelitian ini menggunakan metode Rancangan Acak Lengkap (RAL) yang terdiri dari dua faktor perlakuan. Faktor pertama adalah macam media tanam, yang terdiri dari 3 macam (P1 : pupuk kandang sapi, P2: pupuk kandang kambing, dan P3: pupuk kandang ayam). Faktor yang kedua yaitu pemberian PGPR yang terdiri dari 3 macam (K1: $0 \mathrm{ml} / \mathrm{L}, \mathrm{K} 2: 10 \mathrm{ml} / \mathrm{L}$, dan $\mathrm{K} 3: 20 \mathrm{ml} / \mathrm{L}$ ). Parameter pengamatan terdiri atas jumlah stek hidup, panjang tunas, panjang akar, jumlah daun, dan jumlah akar. Hasil penelitian menunjukkan bahwa Perlakuan P1 (pemberian pupuk kandang sapi) memberikan hasil terbaik pada jumlah stek hidup, panjang tunas, jumlah daun, jumlah akar, serta panjang akar. Jumlah stek hidup terbanyak 2,33 (P1), sedangkan yang terendah 1,89 (P3), kemudian panjang tunas tertinggi 4,78 (P1), sedangkan yang terendah 3,64 (P3), kemudian jumlah daun terbanyak 5,33 (P1), sedangkan yang terendah 3,67 (P3), kemudian jumlah akar terbanyak 6,89 (P1), sedangkan yang terendah 5,26 (P3). Perlakuan K3 (pemberian konsentrasi PGPR $20 \mathrm{ml} / \mathrm{L}$ ) memberikan hasil terbaik pada jumlah stek hidup, jumlah daun, jumlah akar, panjang tunas, dan panjang akar. Panjang tunas tertinggi 4,48 (K3), sedangkan yang terendah 3,39 (K1), kemudian panjang akar tertinggi 14,38 (K3), sedangkan yang terendah 9,74 (K1). Interaksi perlakuan $\mathrm{P}$ x K menunjukkan hasil terbaik terhadap jumlah stek hidup dan panjang akar, panjang tunas, serta pada panjang akar. Kombinasi perlakuan P1K3 (pemberian media pupuk kandang sapi dan konsentrasi PGPR $20 \mathrm{ml} / \mathrm{L}$ ) memberikan hasil terbaik pada pertumbuhan stek karet kebo.
\end{abstract}

Kata kunci : jumlah stek hidup, karet kebo, macam media tanam

\section{ABSTRACT}

This research aims to find out the influence of various planting media and the provision of PGPR concentrations on the success of kebo rubber plant cuttings (Ficus elastica). The study used the Complete Randomlzed Design (RAL) method consisting of two treatment factors. The first factor was the type of planting media, which consists of 3 types (P1: cow manure, P2: goat manure, and P3: chicken manure). The second factor was the administration of PGPR consisting of 3 types $(\mathrm{K} 1: 0 \mathrm{ml} / \mathrm{L}, \mathrm{K} 2: 10 \mathrm{ml} / \mathrm{L}$, and $\mathrm{K} 3: 20 \mathrm{ml} / \mathrm{L}$ ). The observation parameters consist of the number of living cuttings, the length of the shoots, the length of the roots, the number of leaves, and the number of roots. The results showed that P1 treatment (feeding of cow manure) gave the best results on the number of live cuttings, the length of shoots, the number of leaves, the number of roots, and the length of the roots. The lowest number of live cuttings was $2.33(\mathrm{P} 1)$, while the lowest was 1.89 (P3), then the highest shoot length was 4.78 (P1), while the lowest was 3.64 (P3), then the lowest number of leaves was 5.33 (P1), while the lowest was 3.67 (P3), then the lowest number of roots was 6.89 (P1), while the lowest was 5.26 (P3). K3 treatment (pgpr concentration of $20 \mathrm{ml} / \mathrm{L}$ ) gives the best results on the number of live cuttings, the number of leaves, the number of roots, the length of the shoots, and the length of the roots. The highest shoot length was 4.48 (K3), while the lowest was 3.39 (K1), then the highest root length was 14.38 (K3), while the lowest was 9.74 (K1). The interaction of $\mathrm{P} \times \mathrm{K}$ treatment showed the best results on the number of live cuttings and root length, the length of the buds, as well as on the length of the roots. The combination of P1K3 treatment (the provision of cow manure media and PGPR concentration of $20 \mathrm{ml} / \mathrm{L}$ ) provides the best results on the growth of kebo rubber cuttings.

Keywords: kebo rubber plant, kinds of planting media, number of live cuttings 
Agrisaintifika

Jurnal Ilmu-Ilmu Pertanian

Vol. 5, No. 2, 2021

Roslyana et al., 2021

\section{PENDAhULUAN}

Tanaman karet kebo (Ficus elastica) adalah tanaman yang asalnya dari India. Karet kebo dapat mencapai ketinggian 8$40 \mathrm{~m}$. Tumbuhan ini memiliki daun tunggal yang memanjang (elips) dan bertangkai panjang, daun tua berwarna hijau kemerahan dan warna daun muda merah. Karet kebo memiliki banyak akar aerial yang menjadi penopang yang kuat ketika dewasa. Karet kebo memerlukan cahaya matahari penuh, serta tanah yang kaya humus dan drainase yang baik. Karet kebo menghasilkan getah karet (lateks) yang dapat menyebabkan iritasi jika mengenai kulit dan mata. Dahulu tanaman karet kebo pernah ditanam secara besar - besaran sebagai penghasil lateks, namun kemudian terdesak oleh penghasil lateks lainnya yakni Hevea brasiliensis (Dwiyani., 2013).

Karet kebo mempunyai rasa yang netral dan cukup pedas. Sebagian zat sintetis yang terkandung dalam karet kebo elastis mengingat lateks untuk jenis campuran elastis (lateks) (Rahmawati, dkk., 2018). Pada akar dan kulit batang terdapat saponin, flavonoid, dan polifenol. Hal ini sesuai Handayani, dkk (2020) bahwa daun karet kebo elastis mengandung tanin, polifenol dan saponin.

Selain tumbuhannya dapat dimanfaatkan untuk produksi kayu, tumbuhan hutan juga dapat dimanfaatkan untuk obat tradisional, untuk penyegar udara dan dimanfaatkan untuk tanaman hias. Masyarakat Indonesia sudah sejak dahulu mengetahui dan menggunakan pengobatan konvensional untuk mengobati penyakitnya. Banyak sekali jenis tumbuhan di sekitar kita yang manfaatnya untuk obat tradisional maupun tanaman hias. Salah satu contoh yaitu karet kebo (Ficus elastica) (Rahmawati, dkk,. 2018).

Perbanyakan tanaman karet kebo seringkali dilakukan dengan cara vegetatif, yaitu melalui cara stek. Stek adalah pemuliaan tumbuhan dengan menanam satu bagian tumbuhan. Bagian tumbuhan dapat dikembangkan untuk diperbanyak antara lain bagian akar, daun, serta batang. Tanaman yang dibuat dengan stek memiliki kemiripan diantaranya, hal usia, tinggi tanaman, dan tahan penyakit. Demikian juga, kita berhasil untuk mendapatkan tanaman ideal dalam jangka waktu yang cukup singkat. Jenis tumbuhan yang dapat ditebang sebagian besar adalah tumbuhan dikotil, ini karena tumbuhan dikotil mempunyai kambium. Stek dapat dibagi menjadi stek batang, stek daun, dan stek akar (Anonim, 2021).

Dalam stek karet kebo juga membutuhkan pemacu untuk merangsang pertumbuhan akar tanaman, maka pemberian PGPR perlu dilakukan. PGPR yaitu mikroorganisme yang hidup di perakaran tumbuhan. Mikroba ini hidup berkelompok dalam keadaan menutupi perakaran tanaman. Untuk tumbuhan, keberadaan mikroba ini sangat baik.

PGPR pertama kali dikaji oleh Kloepper dan Scroth pada tahun 1981 untuk menggambarkan organisme mikroskopis tanah yang memiliki ruang akar tanaman yang diinokulasi melalui benih tanaman dan terbukti memperluas perkembangan tanaman. PGPR ada di sekitar perakaran, akar yaitu sumber kehidupan tumbuhan, ada pertukaran udara, nutrisi, penguraian bahan organik, dan sebagainya. Manfaat PGPR untuk tanaman adalah memiliki kemampuan untuk meningkatkan perkembangan dan pertumbuhan akar dan mencegah penyakit dan bahaya karena serangan hama. Manfaat lain adalah untuk tambahan media tanam dan pupuk kandang untuk mempersingkat waktu penguraian bahan organik tersebut (Anisa, 2019).

Pupuk kandang ialah olahan kotoran hewan ternak yang diberikan pada lahan pertanian untuk memperbaiki kesuburan dan struktur tanah. Zat hara yang dikandung pupuk kandang tergantung dari 
sumber kotoran bahan bakunya. Pupuk kandang ternak besar kaya akan nitrogen, dan mineral logam, seperti magnesium, kalium, dan kalsium. Namun demikian, manfaat utama pupuk kandang adalah mempertahankan struktur fisik tanah sehingga akar dapat tumbuh secara baik. Dengan diberikan pupuk kandang maka daya menahan air dan kation-kation tanah meningkat, sehingga apabila diberikan pula pupuk buatan maka pencucian oleh air hujan dan erosi dapat dihambat. Pemberian (Melsasall, dkk, 2019).

\section{BAHAN DAN METODE}

Penelitian dilaksanakan Februari 2021 sampai dengan Juni 2021 di Dusun Manggung, Desa Sukorejo, Kecamatan Musuk, Kabupaten Boyolali. Dengan ketinggian 700-1000 meter di atas permukaan laut.

\subsection{Bahan}

Bahan yang dipakai dalam pengujian ini diantaranya, stek batang karet kebo (Ficus elastica), tanah, pupuk sapi, pupuk kambing, pupuk ayam, sekam padi, PGPR.

Alat yang dipakai untuk pengujian ini diantaranya polybag, alat tulis, papan nama, cangkul, timbangan, kamera, wadah ember, serta penggaris.

\subsection{Metode}

Penelitian ini menggunakan Rancangan Acak Lengkap (RAL) yang terdiri dari 2 faktor perlakuan, yaitu jenis media tanam $(P)$ yang terdiri dari $P 1$ (pupuk kandang sapi, sekam, tanah), P2 (pupuk kandang kambing, sekam, tanah), P3 (pupuk kandang ayam, sekam, tanah).

Perlakuan selanjutnya adalah pemberian konsentrasi PGPR $(\mathrm{K})$, yang terdiri dari $\mathrm{K} 1 \quad$ (PGPR $0 \mathrm{ml} / \mathrm{L}), \mathrm{K} 2$ (PGPR $10 \mathrm{ml} / \mathrm{L}$ ), K3 (PGPR $20 \mathrm{ml} / \mathrm{L}$ ). Pembuatan media tanam adalah kombinasi pupuk kandang sapi, sekam, dan tanah dengan proporsi 1:1:1, kombinasi tanah, pupuk kandang kambing, sekam 1:1:1, dan kombinasi pupuk kandang ayam, tanah, sekam 1:1:1. Kemudian memasukkan media tanam tersebut ke polybag yang telah diatur sebelumnya.

\section{HASIL DAN PEMBAHASAN}

Rangkuman penelitian pegaruh macam media tanam dan konsentrasi PGPR pada keberhasilan stek karet kebo (Ficus elastica) ditampilkan pada tabel. 1.

Dari rangkuman hasil penelitian perlakuan $\mathrm{P}$ atau jenis media tanam (media pupuk kandang sapi, pupuk kandang kambing, pupuk kandang ayam) berpengaruh nyata pada parameter jumlah stek hidup, panjang tunas, jumlah akar, serta jumlah daun, tidak berpengaruh nyata pada parameter panjang akar. Perlakuan P1 (media pupuk kandang sapi) memberikan hasil terbaik pada pertumbuhan stek karet kebo. Hal tersebut dibuktikan dengan hasil hitung analisis sidik ragam. Seperti yang diungkapkan oleh Hariatik (2016) bahwa dalam pupuk kandang sapi terkandung unsur hara makro dan mikro, yang kesemuanya membantu memberikan nutrisi untuk kepentingan pertumbuhan dan perkembangan tanaman karet kebo.

Perlakuan $\mathrm{K}$ atau pemberian PGPR $(0 \mathrm{ml} / \mathrm{L}, 10 \mathrm{ml} / \mathrm{L}, 20 \mathrm{ml} / \mathrm{L})$

tidak berpengaruh nyata pada jumlah stek hidup, jumlah daun, serta jumlah akar, berpengaruh nyata pada panjang tunas, dan berpengaruh sangat nyata pada panjang akar. Pada perlakuan K3 pemberian PGPR 20ml/L menghasilkan interaksi terbaik pada pertumbuhan stek tanaman. Hal ini disebabkan oleh semakin tinggi pemberian PGPR pada tanaman menyebabkan peningkatan jumlah mikroorganisme yang terkandung dalam PGPR dan peningkatan pertumbuhan tanaman. Hal tersebut sejalan penilaian (Widiastoety, 2014) bahwa penambahan PGPR membuat fungsinya menjadi lebih baik dan efektif karena lebih banyak 
Agrisaintifika

Jurnal Ilmu-Ilmu Pertanian

Vol. 5, No. 2, 2021

Roslyana et al., 2021

mikroorganisme pada akar termasuk Psedumonas fluerences yang dapat Meningkatkan zat atau hormon auksin, giberelin dan sitokinin sehingga berpengaruh terhadap perkembangan dan pertumbuhan tanaman, terutama pada pertumbuhan panjang tunas.

Interaksi perlakuan macam media tanam tanam $(P)$ dan perlakuan pemberian konsentrasi PGPR (K) memperlihatkan berpengaruh sangat nyata pada jumlah stek hidup dan panjang akar. Hal tersebut dapat disimpulkan bahwa interaksi macam media tanam dan PGPR saling bersinergi pada pertumbuhan stek karet kebo (Balitbangtan, dkk, 2018). Namun interaksi diantara media tanam dan PGPR tidak berpengaruh nyata pada panjang tunas dan jumlah akar, serta berpengaruh nyata pada jumlah daun. Hal ini dikarenakan jenis media pupuk kandang sapi dan pemberian PGPR 20ml/L dapat menghasilkan hasil yang paling baik pada pertumbuhan stek tanaman karet kebo (Ningrum, dkk, 2017).

Tabel. 1. Rangkuman hasil penelitian macam media tanam dan konsentrasi PGPR terhadap keberasilan stek tanaman karet kebo.

\begin{tabular}{|c|c|c|c|c|c|}
\hline \multirow{2}{*}{ Parameter } & \multirow{2}{*}{ Konsentrsi PGPR } & \multicolumn{3}{|c|}{ Macam media tanam } & \multirow{2}{*}{ Rerata } \\
\hline & & P1 & P2 & P3 & \\
\hline \multirow{4}{*}{$\begin{array}{l}\text { Jumlah stek } \\
\text { hidup }\end{array}$} & $\mathrm{K} 1$ & $1,67 \mathrm{a}$ & $2,00 \mathrm{a}$ & $2,00 \mathrm{a}$ & 1,89 \\
\hline & $\mathrm{K} 2$ & $2,33 \mathrm{a}$ & $2,00 \mathrm{a}$ & $2,00 \mathrm{a}$ & 2,11 \\
\hline & K3 & $3,00 \mathrm{~b}$ & $1,67 a$ & $1,67 \mathrm{a}$ & 2,11 \\
\hline & Rerata & $2,33 \mathrm{~b}$ & $1,89 \mathrm{a}$ & $1,89 \mathrm{a}$ & \\
\hline \multirow{4}{*}{$\begin{array}{l}\text { Panjang tunas } \\
\text { (cm) }\end{array}$} & $\mathrm{K} 1$ & 3,09 & 3,50 & 3,59 & $3,39 a$ \\
\hline & $\mathrm{K} 2$ & 5,26 & 4,05 & 3,83 & $4,38 \mathrm{~b}$ \\
\hline & K3 & 6,01 & 3,94 & 3,50 & $4,48 \mathrm{~b}$ \\
\hline & Rerata & $4,79 \mathrm{~b}$ & $3,83 \mathrm{a}$ & $3,64 \mathrm{a}$ & \\
\hline \multirow{4}{*}{$\begin{array}{l}\text { Panjang akar } \\
\text { (cm) }\end{array}$} & $\mathrm{K} 1$ & $7,15 \mathrm{a}$ & $11,91 b$ & $10,10 a$ & $9,72 \mathrm{a}$ \\
\hline & $\mathrm{K} 2$ & $14,38 b$ & $13,45 b$ & $11,59 b$ & $13,14 b$ \\
\hline & K3 & $20,30 c$ & $11,61 a$ & $11,22 b$ & $14,38 b$ \\
\hline & Rerata & $13,94 b$ & $12,32 b$ & $10,97 a$ & \\
\hline \multirow{4}{*}{ Jumlah daun } & $\mathrm{K} 1$ & $3,11 \mathrm{a}$ & $3,89 \mathrm{a}$ & $3,78 \mathrm{a}$ & 3,59 \\
\hline & $\mathrm{K} 2$ & $5,44 \mathrm{~b}$ & $4,67 \mathrm{a}$ & $3,67 \mathrm{a}$ & 4,59 \\
\hline & K3 & $7,44 \mathrm{c}$ & $3,56 \mathrm{a}$ & $3,56 \mathrm{a}$ & 4,85 \\
\hline & Rerata & $5,33 \mathrm{~b}$ & $4,04 \mathrm{a}$ & $3,67 \mathrm{a}$ & \\
\hline \multirow{4}{*}{ Jumlah akar } & K1 & 4,67 & 5,44 & 5,44 & 5,18 \\
\hline & $\mathrm{K} 2$ & 7,11 & 5,89 & 5,33 & 6,11 \\
\hline & K3 & 8,89 & 5,67 & 5,00 & 6,52 \\
\hline & Rerata & $6,89 \mathrm{~b}$ & $5,67 \mathrm{a}$ & $5,26 \mathrm{a}$ & \\
\hline
\end{tabular}

Keterangan : Angka-angka yang diikti huruf yang berbeda pada kolom yang sama menunjukkanberbeda nyata pada uji DMRT 5\% 
Jurnal Ilmu-Ilmu Pertanian

Vol. 5, No. 2, 2021

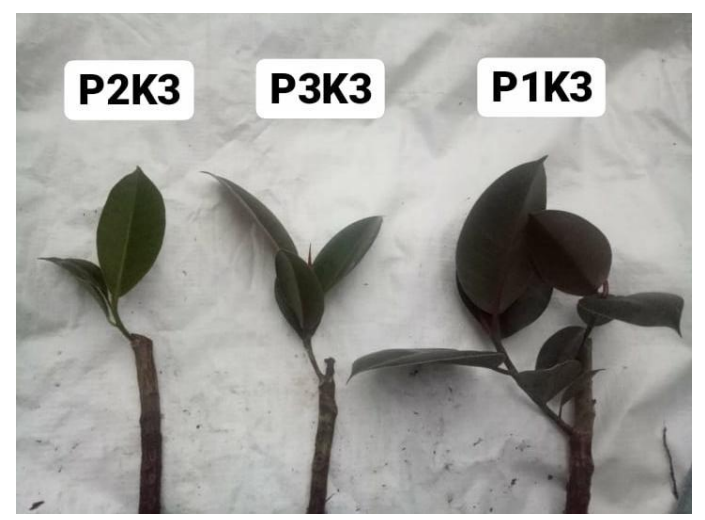

Gambar 1.

\section{SIMPULAN}

Perlakuan $\mathrm{P}$ atau jenis media tanam (Pupuk kandang ayam, pupuk kandang sapi, pupuk kandang kambing) berpengaruh nyata pada jumlah stek hidup, panjang tunas, jumlah daun, serta jumlah akar.

Pada perlakuan K3, pemberian PGPR $20 \mathrm{ml} / \mathrm{L}$ menghasilkan hasil terbaik pada pertumbuhan stek tanaman karet kebo.

Kombinasi perlakuan P1K3 (Media pupuk kandang sapi dan PGPR 20ml/L) menghasilkan hasil terbaik pada pertumbuhan stek karet kebo dari pada kombinsi perlakuan yang lain. Interaksi perlakuan $\mathrm{P} \times \mathrm{K}$ menunjukkan pengaruh sangat nyata pada jumlah stek hidup dan panjang akar, berpengaruh nyata pada panjang tunas, dan berpengaruh sangat nyata pada panjang akar.

\section{DAFTAR PUSTAKA}

Anisa, H. (2020) 'Pengaruh Konsentrasi dan Interval Pemberian PGPR (Plant Growth Promoting Rhizobacteria) Terhadap Pertumbuhan dan Produksi Bunga Kol (Brassica oleraceae var. botrytis L.)', Biofarm: Jurnal IImiah Pertanian, 15(2).doi:10.31941/biofarm.v15i2.11 39.

Anonim (2021) Belajar Mengenal Stek: Salah satu alternatif perbanyakan massal secara vegetatif, Balai Besar Litbang Ekosistem Hutan Dipterokarpa. Available at: https://www.diptero.or.id/belajar- mengenal-stek-salah-satu alternatifperbanyakan-massal-secaravegetatif/.

Ardiyanto, F, M,. Karyawati, A, S,. \& Sitompul, S, M, . (2017) 'Pengaruh frekuensi pemberian dan konsentrasi Rhizobakteri pemacu perumbuhan tanaman terhadap pertumbuhan dan hasil kedelai sayur (Glycine max L . Merrill)', Jurnal produksi tanaman, 5(11), pp. 1762-1767. Available at:http://protan.studentjournal.ub.ac.i d/index.php/protan/article/view/568.

Atmaja, I. W. D. (2001) Bioteknologi Tanah. Bali: Jurusan Tanah Fakultas Pertanian Universitas Udayana.

Balitbangtan, A. and Kailaku, T. E. (2018) 'Prosiding Seminar Nasional \& Rakernas Perhimpunan Agronomi Indonesia (Peragi)" Peran Teknologi Agronomi dalam Pengembangan Sumber Daya Pangan Lokal untuk Kedaulatan Pangan Indonesia Reviewer : Penyunting :'

Dwiyani, R. (2013) Mengenal Tanaman Pelindung Disekitar Kita. Bali: Universitas Udayana.

Handayani, S., Kurniawati, I. and Abdul Rasyid, F. (2020) 'Uji Aktivitas Antioksidan Ekstrak Daun Karet Kebo (Ficus Elastica) dengan Metode Peredaman Radikal Bebas Dpph (1,1-Diphenyl-2Picrylhydrazil)', Jurnal Farmasi Galenika (Galenika Journal of Pharmacy) (e-Journal), 6(1), pp. 141-150. doi: 10.22487/j24428744.2020.v6.i1.150 22.

Hariatik (2016) 'Perbandingan Unsur NPK pada Pupuk Organik Kotoran Sapi dan Kotoran Ayam dengan Pembiakan Mikro Organisme Lokal', (July), pp. 1-23.

Melsasail, L. and Kamagi, Y. E. B. (2019) 'Analisis Kandungan Unsur Hara Pada Kotoran Sapi Di Daerah Dataran Tinggi Dan Dataran Rendah', Cocos, 2(6).

Ningrum, W. A., Wicaksono, K. P. and Tyasmoro, S. Y. (2017) 'Pengaruh Plant Growth Promoting Rhizobacteria (PGPR) dan Pupuk Kandang Kelinci Terhadap 
Roslyana et al., 2021
Pertumbuhan dan Produksi
Tanaman Jagung Manis (Zea mays saccharata)', Jurnal Produksi Tanaman, 5(3), pp. 433-440.

Rahmawati, E., M. P. Putri., dan A. B. M. (2018) 'Ekstraksi dan karakterisasi pektin daun karet kebo (Ficus elastica Roxb .)', Prosiding Seminar Nasional Sains, Teknologi dan Analisis, (1), pp. 111-114.

Widiastoety, D. (2014) 'Pengaruh Auksin dan Sitokinin Terhadap Pertumbuhan Planlet Anggrek Mokara ( Effect of Auxin and Cytokinin on the Growth of Mokara Orchid Plantlets )', Hortikultura, 24(3), pp. 230-238. 